outpatient clinic did not elicit a true picture of morbidity. The possibility that the doctor and being in a clinic inhibit a patient's inclination to report side effects led us to produce a questionnaire and to arrange for a sympathetic, non-medical member of the team to distribute and explain it. The women were asked to complete the form at home in the hope that they would then express their reactions to the treatment more accurately.

We recommend that this method is a more appropriate one of assessing side effects, and similar experiences were reported by $\mathrm{H}$ Bush at a symposium of the Royal College of Physicians, London, in May 1980. If such questionnaires were more widely used the toxicity of various chemotherapy regimens could be compared more objectively.

Troublesome side effects were much more common and severe in those women receiving the five-drug regimen, and the therapeutic case for using such a combination has to be a strong one. Side effects were also seen in an appreciable number of patients receiving single-agent chemotherapy, and claims that single-agent chemotherapy (using chlorambucil in this dosage) should be used as an adjuvant because it is "non-toxic" should therefore be regarded with caution.

The proportion of patients who had experienced severe side effects in the trial was considerable; hence such treatment is justifiable only if it will result in a substantial increase in prognosis. A major ambition of doctors should be to improve the wellbeing of patients. Any treatment which causes distress or illness should be given only when there is good evidence of future benefit. The results of this survey contributed to our decision to stop this study of adjuvant chemotherapy.

We are grateful to Miss Rosemary Fisher for her valuable advice in designing the questionnaire and thank the patients for their help and interest.

Requests for reprints should be sent to Miss G A Walsh, Secretary, Breast Unit, Royal Marsden Hospital, Fulham Road, London SW3 6JJ.

\section{References}

1 Fisher B, Carbone P, Economou SG, et al. L-Phenylalanine mustard (L-Pam) in the management of primary breast cancer. $N$ Engl $\mathcal{F}$ Med 1975 ;292:117-22.

2 Bonadonna G, Brusamolino E, Valagussa P, et al. Combination chemotherapy as an adjuvant treatment in operable cancer. $N \mathrm{Engl} \mathrm{f} \mathrm{Med}$ $1976 ; 294: 405$.

${ }^{3}$ Anonymous. Major advance in breast cancer therapy. $N$ Engl $\mathcal{f}$ Med $1976 ; 294: 440$.

${ }^{4}$ Anonymous. Treating breast cancer-true light or false dawn ? Br Med $\mathcal{f}$ 1976 ;ii :263.

${ }^{5}$ Bonadonna G, Rossi A, Valagussa $P$, et al. The CMF program for operable breast cancer with positive axillary nodes: updated analysis on the disease-free interval, site of relapse and drug tolerance. Cancer $1977 ; 39: 2904-15$.

${ }^{6}$ Fisher B, Glass A, Redmond C, et al. L-Phenylalanine mustard (L-Pam) in the management of primary breast cancer: an update of earlier findings and a comparison with those utilizing L-PAM plus 5-fluorouracil (5-FU). Cancer 1977;39:2883-3903.

(Accepted 22 October 1980)

\title{
Prophylaxis of infection after appendicectomy: a survey of current surgical practice
}

\author{
W B CAMPBELL
}

\section{Summary and conclusions}

Two hundred and eighty questionnaires were sent to junior surgical staff throughout England inquiring about their use of systemic antibiotic prophylaxis, topical antibacterial agents, and surgical drainage in appendicectomy. One hundred and seventy-five $(63 \%)$ replies were received from 81 of the 87 hospitals included in the survey. Prophylactic systemic antibiotics were used by 78 surgeons $(46 \%)$ when operating on a normal appendix but by $168(99 \%)$ when the organ had perforated. Most surgeons started antibiotics before operation, but proportionately fewer did so when the appendix was gangrenous or perforated. Patients with severe contamination tended to receive longer courses of antibiotics, although the duration of administration varied considerably. Metronidazole was included in over $95 \%$ of all the prophylactic regimens and was often combined with other drugs when the appendix was gangrenous and perforated. Topical antibacterial agents were applied to the wound routinely by only 45 surgeons (26\%), although 106

\footnotetext{
Department of General Surgery, Frenchay Hospital, Bristol BS16 1LE

W B CAMPBELL, MRCP, FRCS, registrar in surgery (present appointment: surgical registrar, University Department of Surgery, Bristol Royal Infirmary, Bristol BS2 8HW)
}

(61\%) used them sometimes. Povidine-iodone was the agent most commonly used. Only 98 surgeons (56\%) ever drained appendicectomy wounds, while 135 (77\%) sometimes drained the peritoneal cavity.

Evidence suggests that present methods of giving systemic antibiotic prophylaxis should continue, but that topical agents and surgical drainage are perhaps unnecessary when surgeons are confident of the efficacy of the systemic treatment used.

\section{Introduction}

Over the past 20 years many reports have assessed different methods of reducing infection after appendicectomy. The techniques examined have included surgical drainage, the application of topical agents to the wound, and the administration of prophylactic systemic antibiotics. Although the general principle of systemic prophylaxis is now well established, opinion seems to vary widely regarding which patients require antibiotics, the optimum time to start the drugs, and the duration of administration. Furthermore, topical agents are still commonly used, although whether they confer much benefit compared with systemic drugs is not entirely clear.

The impact on everyday surgical practice of results of studies on antibiotics in appendicectomy has not been assessed. I therefore sent 280 questionnaires to junior surgical staff asking for details of the prophylactic measures used in their unit to prevent infection after appendicectomy. 


\section{Methods}

The questionnaires were addressed to the registrar or senior house officer of 280 consultant general surgeons throughout England. These are the members of a surgical team who usually perform appendicectomies and supervise prescription of any prophylactic antibiotics. To minimise any bias due to common local policies 20 questionnaires were sent to each of the 14 health regions in England. No hospital was

TABLE I-Use of prophylactic systemic antibiotics in appendicectomy

\begin{tabular}{lcc}
\hline State of appendix & $\begin{array}{c}\text { No (\%) using } \\
\text { antibiotic }\end{array}$ & $\begin{array}{c}\text { No (\%) not using } \\
\text { antibiotic }\end{array}$ \\
\hline Normal & $78(46)$ & $92(54)$ \\
Inflamed & $97(57)$ & $73(43)$ \\
Gangrenous & $147(86)$ & $23(14)$ \\
Perforated & $168(99)$ & $2(1)$ \\
\hline
\end{tabular}

TABLE II-Time of starting antibiotics

\begin{tabular}{lrcc}
\hline & \multicolumn{3}{c}{ No (\%) starting antibiotics: } \\
\cline { 2 - 4 } State of appendix & Before operation & At operation & After operation \\
& & & \\
\hline Normal & $73(93)$ & $3(4)$ & $2(3)$ \\
Inflamed & $83(86)$ & $9(9)$ & $5(5)$ \\
Gangrenous & $97(66)$ & $41(28)$ & $9(6)$ \\
Perforated & $107(64)$ & $52(31)$ & $9(5)$ \\
\hline
\end{tabular}

questionnaire was fairly uniform, and at least one reply was received from 81 of the 87 hospitals in the survey.

Prophylactic systemic antibiotics-Five of the 175 responders stated that they were participating in trials of prophylactic antibiotics but gave no further details. They were therefore excluded from the results, leaving 170 questionnaires for analysis. The state of the appendix was graded as normal, inflamed, gangrenous, or perforated. Table I shows the numbers of surgeons using antibiotics in each state. Table II shows the times of starting systemic antibiotic prophylaxis. Preoperative antibiotics were supplemented by additional drugs at or after operation for a gangrenous appendix by 29 surgeons $(17 \%)$, and for a perforated appendix by $55(32 \%)$. Table III shows the number of doses or duration of antibiotic treatment. When a varying duration was specified (for example, three to five days) the shorter period is quoted. Table IV summarises the many different antibiotic regimens that were used. Metronidazole was included in $97 \%$.

Topical agents-Of the 175 questionnaires analysed, two did not include a reply to this section. One hundred and six surgeons (61\%) sometimes used a topical agent, but only $45(26 \%)$ did so routinely. Altogether 118 preferences were stated, as some surgeons specified alternatives: povidone-iodine was used by $74(63 \%)$; polyantibiotic spray by $19(16 \%)$; ampicillin powder by seven $(6 \%)$; noxythiolin by five $(4 \%)$; hydrogen peroxide, chlorinated lime (Eusol), Milton antiseptic, and malic acid mixture each by two (7\%); and cephazolin, cephradine, chloramphenicol, chlorhexidine plus cetrimide, and water each by one $(4 \%)$.

Wound drainage-Questions on wound drainage were designed to ascertain whether any of the techniques were completely unacceptable to the surgeon. Table V presents the replies.

TABLE III-Duration of administration of systemic antibiotic prophylaxis. (Figures are numbers ( $\%$ ) of responders)

\begin{tabular}{|c|c|c|c|c|c|c|c|c|c|c|c|}
\hline \multirow{2}{*}{ State of appendix } & \multicolumn{4}{|c|}{ No of doses } & \multicolumn{5}{|c|}{ No of days } & \multirow{2}{*}{$\begin{array}{l}\text { Not } \\
\text { stated }\end{array}$} & \multirow{2}{*}{ Total } \\
\hline & 1 & 2 & 3 & 4 & 2 & 3 & 4 & 5 & $\geqslant 7$ & & \\
\hline $\begin{array}{l}\text { Normal } \\
\text { Inflamed } \\
\text { Gangrenous } \\
\text { Perforated }\end{array}$ & $\begin{array}{c}47(60) \\
33(34) \\
15(10) \\
4(2)\end{array}$ & $\begin{array}{l}3(4) \\
2(2) \\
5(3) \\
2(1)\end{array}$ & $\begin{array}{l}7(9) \\
13(13) \\
15(10) \\
8(5)\end{array}$ & $\begin{array}{r}1(1) \\
2(2) \\
5(3) \\
13(8)\end{array}$ & $\begin{array}{r}9(12) \\
15(15) \\
18(12) \\
17(10)\end{array}$ & $\begin{array}{c}6(8) \\
13(13) \\
18(12) \\
23(14)\end{array}$ & $\begin{array}{l}1(1) \\
2(1) \\
4(2)\end{array}$ & $\begin{array}{c}3(4) \\
14(15) \\
47(32) \\
68(41)\end{array}$ & $\begin{array}{l}3(3) \\
16(11) \\
25(15)\end{array}$ & $\begin{array}{l}2(3) \\
1(1) \\
6(4) \\
4(2)\end{array}$ & $\begin{array}{r}78(100) \\
97(100) \\
147(100) \\
168(100)\end{array}$ \\
\hline
\end{tabular}

TABLE IV-Types of antibiotics used in systemic prophylaxis. (Figures are numbers (\%) of responders)

\begin{tabular}{|c|c|c|c|c|}
\hline & \multicolumn{4}{|c|}{ State of appendix } \\
\hline & Normal & Inflamed & Gangrenous & Perforated \\
\hline $\begin{array}{l}\text { Metronidazole alone } \\
\text { Metronidazole + ampicillin } \\
\text { Metronidazole + cephalosporin } \\
\text { Metronidazole + gentamicin } \\
\text { Metronidazole + others } \\
\text { Cephalosporin alone } \\
\text { Gentamicin alone } \\
\text { Ampicillin alone } \\
\text { Penicillin + streptomycin }\end{array}$ & $\begin{array}{c}73(94) \\
3(4) \\
61 \\
2(3)\end{array}$ & $\begin{array}{l}84(87) \\
4(4) \\
5(5) \\
2(2) \\
1(1) \\
1(1)\end{array}$ & $\begin{array}{l}65(44) \\
28(19) \\
32(22) \\
11(7) \\
5(3) \\
2(1) \\
1(1) \\
2(1) \\
1(1)\end{array}$ & $\begin{array}{l}31(18) \\
39(23) \\
52(31) \\
30(18) \\
12(7) \\
\\
1 \\
1\end{array}$ \\
\hline $\begin{array}{l}\text { Ampicillin + gentamicin } \\
\text { Ampicillin }+ \text { cephalosporin }\end{array}$ & & & & $\left.\begin{array}{l}1 \\
1\end{array}\right\}$ \\
\hline Total & $78(100)$ & $97(100)$ & $147(100)$ & $168(100)$ \\
\hline
\end{tabular}

sent more than four questionnaires, regardless of the number of surgeons listed on its staff. Thus six or seven hospitals in each health region received questionnaires. Because a registrar or senior house officer may work for more than one consultant recipients were asked to return any unused questionnaires. Subsequent telephone contact, however, indicated that this had not always been done.

Four questions were posed. (1) Do you ever use prophylactic systemic antibiotics in appendicectomy? (2) What drugs/dose/route do you use in patients with a normal/inflamed/gangrenous/perforated appendix ? (a) before operation ? $(b)$ at operation ? (c) after operation ? (3) Do you use a topical wound antiseptic or antibiotic, and if so what and when (always/sometimes/never)? (4) Do you ever (a) leave the wound open ? (b) drain the peritoneum ? (c) drain the wound ?

\section{Results}

Of the 280 questionnaires sent, $175(63 \%)$ were returned. The geographical distribution of surgeons who did not return their

\section{Discussion}

\section{PROPHYLACTIC SYSTEMIC ANTIBIOTICS}

This survey confirms that systemic antibiotic prophylaxis is now common practice. Although the regimens used vary appreciably, considerable areas of agreement are apparent.

The surgeons who gave antibiotics when removing a normal

TABLE V-Use of surgical drainage in appendicectomy. (Figures are numbers (\%) of responders)

\begin{tabular}{|c|c|c|c|}
\hline & $\begin{array}{l}\text { Wound } \\
\text { left } \\
\text { open }\end{array}$ & $\begin{array}{l}\text { Peritoneum } \\
\text { drained }\end{array}$ & $\begin{array}{l}\text { Wound } \\
\text { drained }\end{array}$ \\
\hline $\begin{array}{l}\text { Sometimes } \\
\text { Never } \\
\text { Not stated }\end{array}$ & $\begin{array}{c}57(33) \\
116(66) \\
2(1)\end{array}$ & $\begin{array}{c}135(77) \\
38(22) \\
2(1)\end{array}$ & $\begin{array}{c}98(56) \\
75(43) \\
2(1)\end{array}$ \\
\hline Total & $175(100)$ & $175(100)$ & $175(100)$ \\
\hline
\end{tabular}


appendix almost always did so (93\%) before the operation and were generally those who gave such prophylaxis to all patients undergoing appendicectomy. The number who claimed to administer preoperative prophylaxis increased with the severity of appendicular inflammation (although how some differentiated between a normal and an inflamed appendix before operation was not clear). The number who started antibiotics at the time of operation also rose with the severity of inflammation, although many surgeons maintain that these drugs are not then prophylactic. Since contamination of the abdominal wound occurs at operation, however, such drugs must be prophylactic against postoperative wound infection. Studies ${ }^{12}$ have shown clearly that the efficacy of systemic antibiotics was greatest if they were in the circulation when the bacteria lodged in the tissues and decreased progressively until they became of no real value when started three hours thereafter. Although these studies indicated that antibiotics are most effective when given preoperatively, they also showed that little is lost by starting them within about one hour after bacterial lodgement. Those who started giving antibiotics postoperatively (3-6\%) still offered their patients some benefit if the drugs were started within three hours.

Quite apart from raising the apparent paradox between diagnostic acumen and indications for operation, the group that gave preoperative antibiotics only when the appendix was diseased prompts the important question of the value of prophylactic antibiotics when a normal appendix is removed. Ninety-two surgeons $(54 \%)$ stated that they did not use antibiotics in such cases. Several studies, ${ }^{3-5}$ however, clearly document infective complications after normal appendicectomy, and these include not only wound infections but also occasionally pelvic abscesses. The incidence of such infections is appreciably reduced by prophylactic antibiotics, which would seem to justify protecting this group of patients.

The large proportion of surgeons (43\%) who did not use antibiotics routinely when the appendix was inflamed is surprising. Even when the appendix was gangrenous $14 \%$ still withheld systemic prophylaxis, but when it was perforated only $1 \%$ considered antibiotics to be unnecessary.

The choice of antibiotics was fairly unanimous. Metronidazole featured in over $95 \%$ of all regimens and was often combined with other drugs when the appendix was gangrenous or perforated. This accords with the findings of clinical studies in appendicectomy. The choice of antibiotics was radically influenced when anaerobic organisms were recognised as the pathogens causing infections after appendicectomy. Their role was first suggested by Veillon and Zuber in $1898,{ }^{6}$ and in 1974 Leigh ${ }^{7}$ showed bacteroides to outnumber all other bacteria grown from appendix fossa swabs. This may explain the relative lack of success of some antibiotics. ${ }^{3}{ }^{8}{ }^{9}$ To attack the anaerobic bacteria specifically Leigh et $a^{10}$ used lincomycin in appendicectomy and reduced the incidence of infection with a single preoperative dose. Evidence also suggests that clindamycin is beneficial. ${ }^{\circ}$ These two antibiotics were not used by surgeons in the present survey. Because of its activity against anaerobes metronidazole has received considerable attention in recent years. Its effectiveness in appendicectomy was first noted by Willis et al, ${ }^{11}$ who showed a significant reduction in postoperative infections caused by bacteroides, although some subsequent results ${ }^{12}$ indicated that an antibiotic with activity against both aerobes and anaerobes might be more advantageous. Metronidazole is superior to systemic ampicillin ${ }^{13}$ and povidone-iodine spray. ${ }^{14}$ An especial attraction of metronidazole is its availability as suppositories, which are both effective and cheap. Most surgeons stated that they used these in preference to the intravenous preparation.

The duration of administration of antibiotic prophylaxis varied considerably, although some broad areas of agreement emerged. A single preoperative dose was used by $60 \%$ of those who gave an antibiotic when removing a normal appendix. Single-dose prophylaxis has been shown to be effective, ${ }^{910} 15$ although its relative merits when compared with longer courses have not been fully evaluated. It appears to be a reasonable choice, however, especially in those cases in which contamination is not severe. In the early successful trials of antibiotic prophylaxis in abdominal surgery ${ }^{16}{ }^{17}$ three doses of antibiotic were given, and several surgeons used this regimen. In some later studies, ${ }^{31112}$ however, much longer courses were given, especially when the contamination was severe, ${ }^{18}$ and this practice is widely followed. When the appendix was normal or inflamed only $4 \%$ and $18 \%$ of surgeons respectively gave five or more days of treatment, whereas the proportions increased to $43 \%$ and $56 \%$ when the appendix was gangrenous and perforated respectively. Many surgeons stated that they varied the duration of administration of antibiotics postoperatively depending on the clinical state of the patient.

\section{TOPICAL ANTIBACTERIAL AGENTS}

Forty-five $(26 \%)$ of the responders always used a topical antibacterial preparation, and a further $61(35 \%)$ sometimes did so. Povidone-iodine, whose benefit Gilmore et al, showed convincingly, ${ }^{18} 19$ was used by $67(63 \%)$ of those who used a topical agent. The second most popular agent was polyantibiotic spray, which was used by 19 surgeons $(16 \%)$. Documented evidence that the incidence of infection is appreciably reduced by applying this preparation to appendicectomy wounds is difficult to find. Neither Longland et $a l^{20}$ nor Gilmore and Martin $^{19}$ showed any such benefit, and earlier trials produced conflicting results. Ampicillin powder was used by seven surgeons $(6 \%)$. Its value in preventing infection has been clearly documented, ${ }^{21-24}$ although Mountain and Seal ${ }^{22}$ showed no benefit in patients with more severe contamination. The importance of evidence such as this is hard to assess, however, since many surgeons combine the topical agents with systemic prophylaxis. Some surgeons admit that the visible application of an antibacterial substance to the wound imparts a certain psychological benefit. Noxythiolin was used as a wound application by five surgeons ( $4 \%$ ) although its value in this role is doubtful. ${ }^{25} 26$

Several other topical agents were used, but each by only one or two surgeons. The choice of chloramphenicol is interesting, because Lari et $a l^{27}$ showed this drug to be effective against all the organisms recovered from operative and postoperative swabs from a series of children undergoing appendicectomy.

\section{SURGICAL DRAINAGE}

Peritoneal drainage in appendicectomy is associated with increased morbidity. ${ }^{319}$ This is not simply because such drainage tends to be used in the more severe cases: Magarey et $a l^{3}$ randomly allocated patients to receive peritoneal drainage and still found an increase in both the duration of fever and the number of discharging wounds in the group who received drainage. Despite this evidence most surgeons $(77 \%)$ drained the peritoneal cavity from time to time after appendicectomy.

Drainage of the wound, on the other hand, was practised by substantially fewer surgeons $(56 \%)$, although some evidence suggests that it is beneficial. Vinnicombe ${ }^{8}$ and Everson and $\mathrm{Nash}^{28}$ stated that wound drainage reduces the incidence of infection, although Gilmore and $\operatorname{Martin}^{19}$ found no such prophylactic value. There is no evidence, however, that wound drainage is attended by any adverse effects.

\section{CONCLUSION}

On the basis of the published evidence, giving prophylactic metronidazole to all patients before appendicectomy would seem reasonable, and nearly half of the surgeons who replied did this. If a normal appendix is found no further drugs need to be given. If there is considerable contamination another antibiotic should 
perhaps be added, and a number of doses given after operation. This practice was followed by nearly a third of surgeons, although a similar proportion began antibiotic treatment only at the time of operation for a gangrenous or perforated appendix.

Applying povidone-iodine to the wound is a simple measure that confers some protection against wound infection and was used occasionally by nearly half of the surgeons in the survey. The available evidence is against peritoneal drainage (which was used by $77 \%$ ), but a wound drain may be advantageous, although only $56 \%$ of the surgeons ever inserted one.

It is possible that topical agents and surgical drainage may be largely abandoned by those who are confident of the efficacy of the systemic antibiotic prophylaxis used.

I thank colleagues throughout the country who completed and returned the questionnaires. Mr L R Celestin, Mr J O Drife, and $\mathrm{Mr} M \mathrm{H}$ Thompson read the article during its preparation and offered valuable advice.

\section{References}

1 Miles AA, Miles EM, Burke J. The value and duration of defence reactions of the skin to the primary lodgement of bacteria. Br $\mathcal{F}$ Exp Pathol 1957; 38:79-96.

2 Burke JF. The effective period of preventive antibiotic action in experimental incisions and dermal lesions. Surgery $1961 ; 50: 161-8$.

3 Magarey CJ, Chant ADB, Rickford CRK, Magarey JR. Peritoneal drainage and systemic antibiotics after appendicectomy. Lancet 1971 ;ii: 179-82.

4 Fine M, Busuttil RW. Acute appendicitis: efficacy of prophylactic preoperative antibiotics in the reduction of septic morbidity. Am $\mathcal{F}$ Surg $1978 ; 135: 210-2$

5 Leigh DA, Simmons K, Norman E. Bacterial flora of the appendix fossa in appendicitis and postoperative wound infection. $\mathcal{f}$ Clin Pathol 1974; 27:997-1000.

${ }^{6}$ Veillon A, Zuber A. Archive de Médicine Expérimentale et d'Anatomie Pathologique 1898;10:517. Cited by Willis et al. ${ }^{11}$

${ }^{7}$ Leigh DA. Indications for antibiotic prophylaxis and treatment in patients undergoing appendicectomy. F Antimicrob Chemother 1978;4:15-23.

8 Vinnicombe J. Appendicectomy wound infection, drainage, and antibiotics. Br F Surg 1964;51:328-31.

${ }^{9}$ Donovan IA, Ellis D, Gatehouse D, et al. One-dose antibiotic prophylaxis against wound infection after appendicectomy: a randomized trial of clindamycin, cefazolin sodium, and a placebo. Br $\mathcal{F}$ Surg $1979 ; 66: 193-6$
${ }^{10}$ Leigh DA, Pease R, Henderson H, Simmons K, Russ R. Prophylactic lincomycin in the prevention of wound infection following appendicectomy: a double blind study. Brf Surg 1976;63:973-7.

11 Willis AT, Ferguson IR, Jones PH, et al. Metronidazole in prevention and treatment of bacteroides infections after appendicectomy. $\mathrm{Br} \mathrm{Med} \mathcal{F}$ $1976 ; \mathrm{i}: 318-21$.

12 Bates T, Touquet VLR, Tutton MK, Mahmoud SE, Reuther JWA. Prophylactic metronidazole in appendicectomy: a controlled trial. $\mathrm{Br} \mathcal{F}$. Surg $1980 ; 76: 547-50$

${ }^{13}$ Pinto DJ, Sanderson PJ. Rational use of antibiotic therapy after appendicectomy. Br Med f 1980;280:275-7.

14 Salem $R$. The prevention of wound infection after appendicectomy. Antisepsis or chemotherapy ? Royal Society of Medicine international congress and symposium series 1979; No 18:115-7.

${ }^{15}$ Ivarsson LE. Single-dose antibiotic prophylaxis in appendicectomy. Acta Chir Scand 1977;143:469-72.

16 Bernard HR, Cole WR. The prophylaxis of surgical infection: the effect of prophylactic antimicrobial drugs on the incidence of infection following potentially contaminated operations. Surgery $1964 ; 56: 151-7$.

12 Polk HC, Lopez-Mayor JF. Postoperative wound infection: a prospective study of determinant factors and prevention. Surgery $1969 ; 66: 97-103$

18 Gilmore OJA, Martin TDM, Fletcher BN. Prevention of wound infection after appendicectomy. Lancet $1973 ; \mathrm{i}: 220-2$.

19 Gilmore OJA, Martin TDM. Aetiology and prevention of wound infection in appendicectomy. Brf Surg $1974 ; 61: 281-7$.

20 Longland CJ, Gray JG, Lees W, Garrett JAM. The prevention of infection in appendicectomy wounds. Br $\mathcal{F}$ Surg $1971 ; 58: 117-9$.

${ }^{21}$ Rickett JWS, Jackson BT. Topical ampicillin in the appendicectomy of wound: report of a double-blind trial. $\mathrm{Br}$ Med f 1969;iv:206-7.

22 Mountain JC, Seal PV. Topical ampicillin in grid-iron appendicectomy wounds. Br f Clin Pract 1970;24:111-5.

${ }^{23}$ Andersen B, Bendtsen A, Holbraad L, Schantz A. Wound infections after appendicectomy. I. A controlled trial on the prophylactic efficacy of topical ampicillin in non-perforated appendicitis. II. A controlled trial $\vec{\omega}$ on the efficacy of delayed primary suture and topical ampicillin in perforated appendicitis. Acta Chir Scand 1972;138:531-6.

${ }^{24}$ Bates T, Down RHL, Houghton MCV, Lloyd GJ. Topical ampicillin in the prevention of wound infection after appendicectomy. Br $\mathcal{F}$ Surg 1974; $61: 489-92$.

${ }^{25}$ Bird GG, Bunch GA, Croft CB, et al. Topical noxythioline antisepsis. Report of a controlled trial. Br $\mathcal{F}$ Surg 1971;58:447-8.

26 Fraser-Moodie A. Prevention of wound infections after appendicectomy. A trial of two procedures. $\mathcal{F} R$ Coll Surg Edinb 1974;19:121-3.

${ }^{27}$ Lari J, Kirk D, Howden R. Bacteriological survey of acute appendicitis in children. Brf Surg 1976;63:643-6.

${ }^{28}$ Everson NW, Nash JR. Management of appendicitis. $\mathrm{Br}$ Med $\mathcal{F} 1976$; ii $: 1390$.

(Accepted 17 October 1980)

\section{SHORT REPORTS}

\section{Papillary carcinoma of the thyroid in two brothers after chest fluoroscopy in childhood}

Thyroid carcinoma rarely occurs in young men. The occurrence of papillary thyroid cancer in two brothers of similar age therefore suggested some common aetiological factor. A family history back to the grandparents and their siblings yielded no evidence of thyroid disease or of multiple polyposis. Both brothers, however, had been exposed to radiation from cardiac screening in childhood.

\section{Case histories}

Case 1-A 33-year-old man presented in 1973 with a painless nodule in the left lobe of the thyroid. He was euthyroid and otherwise fit. At operation a papillary carcinoma in the left lobe of the thyroid and an enlarged retroclavicular lymph node containing carcinoma were removed. He was subsequently treated with ${ }^{131}$ I and remained well with no recurrence.

Case 2-A younger brother of case 1 was 38 when in 1979 he noticed a nodule in the left lobe of the thyroid. He was euthyroid and otherwise well. At operation a papillary carcinoma was found without evidence of spread beyond the thyroid. Near-total thyroidectomy was carried out followed by ${ }^{131}$ I treatment. He remained well without recurrence.

Sections from the thyroid tumours showed similar appearances (figure). Each was a well-differentiated thyroid papillary carcinoma, in places appear- ing encapsulated. The adjacent thyroid tissue showed normal architecture and normal colloid-containing follicles. Inquiry disclosed that the two brothers had undergone detailed fluoroscopic examination of the heart at 11 and 9 years of age respectively because their mother had cardiac disease. The examinations had been carried out abroad, before image intensification was available, and no details of exact radiation exposure were available.

\section{Comment}

Familiar multiple polyposis (Gardner's syndrome) may be associated with the development of papillary thyroid carcinoma in siblings, ${ }^{1}$ but this was excluded in our patients by the negative family history and absence of clinical features (appearances on sigmoidoscopy and barium enema were also normal). The only relevant history was the irradiation that each had received at fluoroscopy. Martin and Olson ${ }^{2}$ concluded that irradiation of the thyroid during cardiac investigations is not negligible and may appreciably increase the risk of cancer.

The association of radiation with the development of thyroid cancer, often some 20-30 years later, is well recognised, though the dose has usually been in the range $2-5$ Gy (200-300 rads). ${ }^{3}$ An increased incidence of cancer may, however, occur after much lower doses, and Pochin ${ }^{4}$ suggested an induction rate of $1 \%$ per Gy ( $1 \%$ per 100 rads). Using data on chest fluoroscopies ${ }^{5}$ as carried out at about the time that our patients were so investigated, we estimate that their thyroids had probably received a radiation dose of $0 \cdot 2-0 \cdot 3 \mathrm{~Gy}$ (20-30 rads). The eventual appearance of papillary cancers 22 and 28 years later confirms 